\title{
Nós. Quem somos?
}

\section{Aproximações em direção a um termo que foge sem fim}

\author{
Álvaro De Angelis \\ temporário em Filosofia na \\ Escola de Brasília e no grupo de pesquisa Anarchai.
}

O principal perigo para a filosofia é a estreiteza na seleção de provas. Esta estreiteza surge a partir das idiossincrasias e timidez de autores específicos, nomeadamente de determinados grupos sociais e de épocas particulares na história da civilização.

A prova, invocada por cima, é arbitrariamente tendenciosa, pelos temperamentos dos indivíduos, pelas provincianidade de grupos e pelas limitações dos esquemas de pensamento.

Alfred North Whitehead. In Process and Reality: an Essay in Cosmology.

Se é possível que a nossa consciência identitária se manifesta como pertencimento a uma estrutura de associações interacionais em ação (Gabriel Tarde) e por uma alteridade constitutiva que abrange inclusive a radicalidade do outro em nossa condição de ser (Emmanuel Levinas), somos um ser que é em um modo particular e plural ao mesmo tempo, em uma condição tanto presente como em devir.

Se esta realidade singular de possibilidades múltiplas procede, tentemos interpretar ou traduzir o que 
estes possíveis como modos de existência podem significar.

Em Latour, a partir do conhecimento dos aspectos relacionais e constitutivos das estruturas animadas em rede, são levantados dois aspectos importantes, que nos identificam em uma aliança entre humanos, não humanos e coisas. Quais sejam, a natureza heterogênea das entidades que se compõem em redes e o caráter distribuído da ação que as animam (Bruno e Santaella, 2011).

Um importante suporte para a teoria do ator-rede vem de Gabriel Tarde:

(...) como bien saben los discípulos de Gabriel Tarde, sociedad siempre ha significado asociación, y no se ha limitado nunca a los humanos. Así que siempre, y de buen agrado, he hablado, como Alphonse de Candolle, de "sociología de plantas", o, como Alfred North Whitehead, de "sociedades estelares" (Latour, 2014).

Nos estudos do cientista De Candolle - autor do primeiro livro que tratou de descrever quantitativamente as redes científicas, publicado em 1837, e que se notabilizou no meio científico ao rebater a tese eugenista do gênio hereditário (Galton, 1869) - é absorvido por Latour a ideia de que a atualização a distintos ambientes é o que contribui fundamentalmente para o desenvolvimento das capacidades dos indivíduos que os compõem (Del Cont, 20o8).

Em Alfred North Whitehead, com seus objetos eternos e suas entidades atuais, Latour coaduna com a visão de que pertencemos a uma realidade de processos atuais interrelacionados. Ou seja, um real como sociedade de ocasiões, uma conjuntidade de processos e individualidades que pode se tornar manifesta através de um nexo que permite suas atualidades no mundo, em virtude de uma objetivação comum (Bernal, 1967, pp. 108 - 109).

Os pensamentos de Tarde, De Candolle e Whitehead constituem os antecedentes privilegiados de toda sociologia das associações e, por extensão, da própria teoria do ator-rede.

À exceção de Alphonse de Candolle, autor que não será aqui examinado, procuraremos desenvolver uma breve aproximação sintética dos trabalhos de Tarde, Latour e Whitehead em seus possíveis e suas associações relacionais. 
O artigo buscará também associar estas aproximações com a contribuição perspectivista de Deborah Danowski e Viveiros de Castro, intencionando rastrear possíveis compossibilidades nesta conjuntura plural da identidade nos termos "nós" e "mundo".

Comecemos por nos aproximar dos conceitos chaves dos pressupostos de Gabriel Tarde: diferença ontogênica, caráter infinitesimal do real e indeterminação do real.

\section{Os possíveis em Gabriel Tarde}

Como imagina Tarde, tudo começa a partir do infinitesimal e todos os retornos são para o mesmo; nada aparece fortuitamente na esfera do finito. E por ser infinita a realidade, nós, enquanto individuações em associação, por consequência, não somos elementos originais, somos antes o resultado de um processo de composição (Tarde, apud Themudo, 2002).

O primeiro princípio da filosofia tardiana é de que a natureza é um universo infinito de seres diferenciados. Existir é diferir. Conforme Tarde, devemos nos concentrar na ordem ontológica da diversidade e na constituição da alteridade. Como ele diz, na alter-ação se encontra a nossa identidade.

Assim, a identidade do que somos não é uma causa; é apenas um produto, um caso limite de diferenciação infinitamente atenuada. A ontologia tardiana se fundamenta no fato de que todos os seres são diferentes. Este é o grande princípio da sua filosofia: a diferença é o alfa e o ômega do universo.

Um segundo princípio afirma a natureza infinitesimal da realidade. Existir é integrar o infinito no finito.

Os seres que vemos no mundo, individuações em torno de nós, são apenas integrações da realidade infinita materializada em estruturas finitas. A realidade é o que existe somente uma vez e dura só um instante" (Tarde, 2007). Estes corpos, estruturas, em um instante seguinte já seguirão acoplados às redes de diferenças, que por sua vez seguirão diferindo.

Nesta perspectiva-mundo, a existência do real é o movimento que vai das possibilidades aos atos, uma vez que tudo o que acontece traz em si uma radiação de possíveis realidades. Assim, a realidade é uma transformação em ato de uma potência do possível.

Uma força latente, uma força potencial, uma força de tensão 
ou de posição, não importa o nome que se dê, não é nada mais senão uma possibilidade entendida nesse último sentido - ou melhor, é simplesmente um feixo de possibilidades semelhantes (ibidem).

Entretanto, nem todo o possível pode tornar-se real, por conta de forças concorrentes, em luta constante para emergir em termos de realidade.

Não fazemos um só movimento, seja corporal, seja mental, sem esmagar milhares de germes, sejam seres vivos, sejam ideias, sem aniquilar mundos possíveis.

Em suma, quando vir este universo, diga a si mesmo que ele deve sua existência à imolação de milhares de outros universos, entre os quais talvez houvesse alguns, apesar de Leibniz, melhores e mais belos que ele... (ibidem).

Por conta dessas possibilidades realizáveis ou não, se poderia até afirmar que os possíveis que não existiram, poderiam ter acontecido se outros encontros tivessem ocorridos. Ou, indo ao futuro, estas possibilidades podem vir a ter lugar na existência.

Sigamos agora para as implicações das entidades atuais, dos objetos eternos e coletivos, pensar se nos provocam, conhecer os rastros das outras possibilidades no mundo.

\section{O associacionismo amplo de Bruno Latour e as realidades processuais em Alfred Whitehead}

A teoria ator-rede tem como principal foco o desejo de diluição da dicotomia entre o social e o natural, inserindo atores humanos e não-humanos em uma mesma teia de associações. Em seus pressupostos, Latour propõe também uma aproximação nada ortodoxa para a compreensão do social: uma outra via, não homogeneizante, através do entendimento da dinâmica das associações que se estabelecem entre 
elementos heterogêneos presentes numa rede de relações (Camillis et al, 2013).

A proposta latouriana é a de não definir o social como um tipo particular de elemento, porém, como um movimento de associações numa reunião de elementos que estão-com no processo-mundo, sejam humanos e não humanos, máquinas ou virtualidades. Assim, em sua constituição, mais do que uma organicidade, o social é um tipo de associação momentânea caracterizada pela maneira como se reúnem suas novas formas (Latour, 2012).

Portanto, Latour propõe que o termo social seja alterado por coletivo, traduzindo esta sociologia de associações e diferenças como uma reunião dos elementos presentificados em uma dada realidade atualizada.

Dialogando com estas possibilidades, podemos dizer que Whitehead entra neste jogo de forma bem contributiva, a partir de seu entendimento de que devemos perscrutar a realidade além do que já está pensado.

Ele parte do pressuposto de que essa realidade está disponível para nós apenas pela experiência que temos dela, uma vez que o estudo do mundo não é realmente o estudo do mundo: é somente o estudo da nossa experiência do mundo (Whitehead, apud Digby, 2014).

Na perspectiva whiteheadiana, os corpos são entidades atuais, constituídos por objetivações individuais irradiadas de uma miríade de ocasiões interconectadas e momentâneas, que permitem experiências das quais se apreende as coisas do mundo, gotas de experiência, complexas e interdependentes (ibidem).

A objetivação é concebida como um ato de experiência, que surge a partir de uma ocasião atual que se completa, onde cada entidade real é uma vibração de experiência que inclui o mundo em seu escopo. Cada entidade real é parte de um processo e não pode ser reduzida a uma descrição somente a partir de uma identidade morfológica (Whitehead, apud Bernal, 1967).

Neste processo, cada entidade real se torna o que é percebendo a sua interconectividade com o mundo, através de um estado de atualização e de devir ao mesmo tempo.

Whitehead descreve um processo de devir no qual cada entidade real primeiramente sente passivamente o universo objetivado (...). 
Essa unificação dura apenas um instante, mas é um momento de pura auto criatividade subjetiva. Uma vez que essa harmonização esteja completa, ou satisfeita, o momento de vivenciar subjetivo termina, como o faz o processo de devir.

Depois de sua satisfação, a entidade real permanece como parte do contexto objetivo para a ocasião seguinte de experiência. Sob essa perspectiva, o próprio universo é um processo, no qual "muitos se tornam um e são ampliados por um" (Digby, 2014).

Nesta perspectiva, a humanidade é um tipo de unidade relacional entre os corpos das entidades humanas e as diversas naturezas, o que inclui a experiência do corpo material e a unidade mental subjetiva. Porém, somente de maneira primária as relações que se processam entre as entidades diferenciadas podem ser entendidas como psicomorfismo (Whitehead, apud Digby, 2014). A diferença entre um organismo vivo e o meio inorgânico é apenas de uma questão de nível (idem). Assim, uma interconexão entre as naturezas, os corpos e as atividades mentais de todas as entidades que compartem um mesmo processo de mundo pode se estabelecer na medida da aproximação e do equilíbrio entre níveis de mente distintivas.

\section{À procura de rastros dos nós no mundo por vir de Danowski e Castro}

Logo que o conceito de antropoceno foi proposto, diversos filósofos e cientistas começaram a apresentar suas interpretações, buscando entender os significados e as ameaças que a realidade deste fenômeno representa.

Para Deborah Danowski e Eduardo Viveiros de Castro, o antropoceno significa o fim de uma época no que concerne à vida das espécies no planeta, "uma coisa como um tempo presente sem esperança de um futuro animador". 
Nestes tempos repletos de controvérsias, um dos aspectos mais incontroversos é a aceleração descontrolada dos efeitos desreguladores do clima na terra.

[Assim,] tudo o que pode ser dito sobre a crise climática se torna, por definição, anacrônico, defasado; e tudo o que deve ser feito a respeito disso é necessariamente muito pouco, e tarde demais (Danowski e Castro, 2014).

Estes autores fazem côro com a tese do poder transformador da civilização humana representar hoje a magnitude de força geológica, um fenômeno objetivo cujos impactos conseguiram a proeza de alterar todo o planeta, numa escala de tempo em que as forças geológicas levam milhões de anos para realizar.

Esta realidade permite conferir à Terra uma condição de "sujeito histórico", "agente político" e "pessoa moral".

Estamos diante de um fim do mundo, no sentido de mundo humano, o fim como resultado de um processo de desvitalização ontológica do ambiente, com efeitos desumanizadores sobre os sobreviventes (...).

O fim do mundo só tem sentido determinado - só se torna ele próprio pensável como possível - se se determina simultaneamente para quem este mundo que termina é mundo" (idem).

O que isto quer dizer? Para nossos autores, "o fim do mundo tem que discutido como algo que é pensado a partir de um nós e que necessariamente tem que incluir o sujeito do discurso sobre esse fim". Mas, que sujeito é este?

O pólo "sujeito" ou "pessoa" parece quase sempre se referir, como vimos, à totalidade da humanidade enquanto espécie; 
mas ele pode se reduzir à "verdadeira" humanidade, isto é, a alguma encarnação sociocultural específica da excelência humana (...), ou, ao contrário, se expandir a uma virtualidade antropomórfica universal (ibidem)

Nesta perspectiva, temos uma verdadeira (re)emergência de Gaia. E temos também a oposição de dois tipos diferentes de humanos numa situação de inimigos, além da arbitrariedade conceitual de dois campos também opostos, cultura e natureza, povoados de humanos e não humanos.

Logo, o antropoceno é o resultado de uma guerra contra Gaia, que trouxe para o mundo humano a intrusão de Gaia, representada nos fenômenos do aquecimento global e desequilíbrio climático. A intrusão de Gaia traz a possibilidade de fim do mundo feito à imagem e semelhança do homem, e nos divide em dois tipos de homens, os culpados e as vítimas do fim do mundo. Dando nome a esses dois tipos - humanos e terranos - Latour alerta que "deve-se levar em conta essa dualidade" (Latour, Gifford Lectures, 2013).

Nesta cartografia identitária, a constituição terrana é o chamado a resistir ao antropoceno, "aprender a viver com ele, mas, contra ele, ou seja, contra nós mesmos, pois o inimigo, em suma, somos nós - os humanos" (Danowski e Castro, 2014). Assim, o antropoceno e tudo que se lhe associa faz parte de um anúncio do fim do humano enquanto um ser separado das possibilidades associativas de Gaia, da irmã-mãe terra, do habitat que lhe deu condições de existir.

Segundo Stengers (apud Danowski, 2014), este acontecimento antropoceno/guerra contra a terra marca no homem a obrigação de sonhar outros sonhos. Que sonho?

A Gaia de Stengers - seja no sentido de que o mundo está ele próprio, enquanto multiverso atravessado por múltiplas ontologias não-humanas, implicado em um devir que exige de nós que aprendamos a segui-lo; seja no sentido de que os Humanos devem dar lugar a esses que Latour chamou de Terranos, isto é, a todos os existentes enquanto partes do mundo (ibidem). 
Danowski e Castro trazem à crosta terrana o pensamento de que falar no fim do mundo é a mesma coisa que falar na necessidade de "imaginar um novo povo, antes que um novo mundo. Sonhar um tipo de povo que o mundo sente falta". Complemento: o tipo de povo que as entidades humanas precisam para continuar a sua tarefa de atualização no mundo. Sonhar uma possibilidade de mundo por vir que este povo pode criar.

Os Terranos são o povo que falta de que falam Deleuze e Guatarri - o povo por vir, capaz de opor uma "resistência ao presente" e assim criar "uma nova terra", o mundo por vir.

Deborah Danowski, Eduardo Viveiros de Castro. In Há mundos por vir?

\section{Juntando os possíveis: A constituição terrana}

Somos um processo irradiado de associações humanas e não humanas em estado atual de permanência. Não somos a individualidade que cada um parece ser. Nesta condição, ao mesmo tempo de devir frequente e objetivação eterna, somos uma espécie de "Nós" que é, embora ainda estejamos por vir.

Somos no real uma consciência processual coletiva, em uma identidade de realidade possível, em um aqui-e-agora que termina e recomeça infinitamente. Jamais fomos as respostas das interrogações dos questionamentos isolados do quem sou humano, perdido nas trevas iluminadas pelo individualismo e o antropocentrismo.

Somos uma identidade não possível de definição redutível, que vive um processo de conexões associadas de coexistência, de oposição e de exclusão entre seres e coisas em constante alteridade.

Se esta identidade pode ser nomeada terrana é algo a ser pensado, considerando as múltiplas conexões que nos envolvem a todos os mundos além do nosso mundo.

Logo, nos (re)conhecer como terranos abre-nos outras possibilidades de ser, individuações em 
associação de processos de nexidade infinita, pós de estrelas, multiplicidades de uma ontologia que une a espécie, a vida e o mundo.

Ps: Como salienta Tarde, a imaginação emancipada e indomável é tanto um perigo quanto um auxiliar para a ciência e a beleza da arte, o que não aconteceria, se ela existisse apenas em vista destas; e a fecundidade da natureza é tanto um perigo quanto um auxiliar para a espécie, o que não aconteceria, se a prodigalidade dos semens tivesse por única finalidade a conservação da espécie.

\section{Referências}

BERNAL, Jorge Enjuto. La filosofia de Alfred North Whitehead. Madrid: Editoral Tecnos, 1967.

BRUNO, Fernanda, SANTAELLA, Lucia et al. Ator-Rede e Cibercultura: As noções de rede e de tradução na obra de Bruno Latour. V Simpósio Nacional ABCIBER. São Paulo, 2011.

BRUNO, Fernanda. Cartografia das controvérsias. Blog. Visibilidade, vigilância e subjetividade nas novas tecnologias de informação e de comunicação. Paris, 2010. <http://dispositivodevisibilidade.blogspot.com.br/2010/10/cartografia-das-controversias-notas-1.html>

DANOWSKI, Deborah, CASTRO, Eduardo Viveiros. Há mundos por vir? Ensaio sobre os medos e os fins. Florianópolis: Desterro, 2014.

DEL CONT, Valdeir. Francis Galton: eugenia e hereditariedade. Sci. stud., São Paulo , v. 6, n. 2, p. 201-218, June 2008 $<$ http://www.scielo.br/scielo.php?script=sci arttext\&pid=S1678-31662008000200004\&lng=en\&nrm=iso >

DIGBY, Nathan. Corpos sociais, naturais: Alfred North Whitehead em materialidade, interpretação social e processo metafísico. Rio de Janeiro: O percevejo Online, v. o6, n. o1, Jan-Jun, 2014, p. 43-62.

FANCHER, R. E. Alphonse de Candolle, Francis Galton, and the early history of the nature-nurture controversy. Journal Hist. Behav. Sci. 1983 Oct;19(4):341-52. Disponível em: $<$ http://onlinelibrary.wiley.com/doi/10.1002/1520-6696(198310)19:4\%3C\%3E1.o.CO;2-3/issuetoc> 
LATOUR, Bruno. ¿El cosmos de quién? ¿Qué cosmopolítica?: Comentarios sobre los términos de paz de Ülrich Beck. Madrid: Rev. Pléyade, v. 14, Jul-Dic, 2014, pp. 43-59.

. Como prosseguir a tarefa de delinear associações? Revista Configurações, 2006, n. 2, pp. 11-27, São Paulo.

LEVINAS, Emmanuel. Entre nós: Ensaios sobre a alteridade. Rio de Janeiro: Vozes, 1997.

MOLINA, José García. ¿Qué es una sociedad? De la filosofía de las apropiaciones a la sociología en la obra de Gabriel Tarde. Madrid, Política y Sociedad, 2011, v. 48, n. 1, pp. 43-58. Disponível em: <http://revistas.ucm.es/index.php/POSO/article/viewFile/poso1111130043a/21428>

. La constitution du social selon Gabriel Tarde. Paris, Sociétés, 2010, v. 4, n. 110,

pp. 119-128.

TARDE, Gabriel. Monadologia e sociedade. Tradução de Paulo Neves. São Paulo: Cosac Naify, 2007. . Monadologia e sociologia. Tradução de Tiago Seixas Themudo. Petrópolis: Vozes, 2003. . Estudios sociológicos. Las leyes sociales. La sociologia. Córdoba: Ediciones Assandri, 1961.

THEMUDO, Tiago Seixas. Gabriel Tarde: Sociologia e subjetividade. Rio de Janeiro: Relume Dumará, 2002.

WHITEHEAD, Alfred North. O conceito de natureza. Tradução de Julio B. Fischer. São Paulo: Martins Fontes, 1993.

. Naturaleza y vida. Buenos Aires: Facultad de Filosofia e Letras, Universidad de Buenos Aires, 1941.

Álvaro De Angelis é temporário em Filosofia na Escola de Brasília e no grupo de pesquisa Anarchai. 